\title{
AN EXPERIMENTAL STUDY OF AUCTIONS VERSUS GRANDFATHERING TO ASSIGN POLLUTION PERMITS
}

\author{
Jacob K. Goeree \\ University of Zurich, \\ California Institute of Technology
}

Karen Palmer

Resources for the Future

\author{
Charles A. Holt \\ University of Virginia
}

William Shobe

University of Virginia

Dallas Burtraw

Resources for the Future

\begin{abstract}
We experimentally study auctions versus grandfathering in the initial assignment of pollution permits that can be traded in a secondary spot market. Low and high emitters compete for permits in the auction, whereas permits are assigned for free under grandfathering. In theory, trading in the spot market should erase inefficiencies due to initial mis-allocations. In the experiment, high emitters exercise market power in the spot market, and permit holdings under grandfathering remain skewed towards high emitters. Furthermore, the opportunity costs of "free" permits are fully "passed through." In the auction, the majority of permits are won by low emitters, reducing the need for spot-market trading. Auctions generate higher consumer surplus and slightly lower product prices in the laboratory markets. Moreover, auctions eliminate the large "windfall profits" that are observed in the treatment with free, grandfathered permit allocations. (JEL: C92, D43, D44, Q58)
\end{abstract}

\section{Introduction}

One of the most important and contentious issues for any cap-and-trade emissions policy is the initial allocation of allowances or "permits." The solution that is generally favored by the regulated firms is to allocate the limited number of permits at no cost in proportion to past emissions levels. This process, known as

The editor in charge of this paper was Stefano DelaVigna.

Acknowledgments: We gratefully acknowledge financial support from the Dutch National Science Foundation (VICI 453.03.606), the Bankard Fund for Political Economy, Mistra's Climate Policy Research Forum (Clipore) and the US Environmental Protection Agency. We would like to thank Helen Bernhard, Noemi Nagi, Thomas Neumeyer, Nina Spiri, and Sean Sullivan for their help with the experiments, and participants at the European Economic Association Meetings (Barcelona, August 2009) for useful comments.

E-mail addresses: Goeree: jacob.goeree@ gmail.com; Holt: holt@ virginia.edu; Palmer: palmer@ $r f f$. org; Shobe: shobe@ virginia.edu; Burtraw: burtraw@rff.org 
"grandfathering," is typically justified on the grounds that if you make firms pay for permits, the result will be a run-up in downstream product prices, for example, electricity. A simple market-based alternative for the initial assignment is to use regularly scheduled auctions.

In the initial phase of the European Emissions Trading System (EU-ETS) greenhouse gas cap-and-trade program, ${ }^{1}$ the participating countries were required to use auctions for at most $5 \%$ of the permit allocations. The resulting "windfall profits" from free allocations created some public dissatisfaction with the cap-and-trade approach to greenhouse gas emissions controls. For instance, one of Europe's largest carbon emitters, the Germany-based RWE, collected windfall profits of about US\$ 6.4 billion in the first three years of EU-ETS. RWE received $30 \%$ of all permits given out, more than any other company in Germany, and was reprimanded by the German antitrust authority in response to complaints about rising electricity prices (at 5\% per year). RWE acknowledged charging its customers for the emission permits, saying that "while it may have received them for free from the government, they still had value in the market place."2

In contrast, the 2008 Regional Greenhouse Gas Initiative (RGGI) required the use of auctions for a minimum of $25 \%$ of the allocation to electricity producers in 10 northeast states in the U.S. In fact, about $90 \%$ of the permits have been sold by auction in the first year of this program, and the auction revenues are being used for "strategic energy initiatives." The EU plans to initiate auctions for a majority of the permits for electricity producers beginning in 2013 and transition to $100 \%$ auctions by 2020 . In the U.S., the Obama administration favors auctions, but the legislation being considered in Congress is largely based on free allocations.

The initial design of the cap-and-trade policy was heavily influenced by political tradeoffs needed to obtain support for strict emissions controls, but a longer-term perspective should be based on economic considerations. A comparison of different allocation methods is complicated by the fact that economic and regulatory conditions are changing over time as is the mix between auctions and grandfathered allocations. This paper uses laboratory experiments to evaluate the economic effects of grandfathered and auction-based allocations, holding the underlying structure of the market constant. We consider two main issues: (1) Will auction-based allocations result in higher prices for the product being produced (i.e., pass through of permit costs)? and (2) Will grandfathered allocations based on historical emissions levels lead to inefficiencies in the way

1. The EU-ETS is the world's largest carbon-trading market with a trade volume of US\$ 80 billion in 2008. The price of a permit to emit one ton of $\mathrm{CO}_{2}$ was approximately $€ 25$ in 2008.

2. See $\langle$ www.nytimes.com/2008/12/11/business/worldbusiness/11 carbon.html . 
that emissions reductions are spread between high-emitting and low-emitting producers? $?^{3}$

The argument that auctioning permits will raise downstream product prices more than grandfathering is inconsistent with economic theory. Tradable permits have an opportunity cost, that is, the price they sell for in secondary markets, even if they are received for free, and this opportunity cost will be reflected in product prices (e.g., Burtraw et al. 2002). The opportunity cost argument is sometimes viewed with skepticism by regulators. Even when the argument is recognized, the resulting windfall profits are viewed with antagonism, as illustrated by the aforementioned RWE example. Another regulatory concern is the possibility that firms with high emissions levels may exploit the market power associated with high permit allocations in the secondary market for permits.

\section{Experimental Design and Procedures}

We conducted a total of 14 sessions, seven in which the initial permit assignment was decided by auction and seven in which it was decided by grandfathering. ${ }^{4}$ In each session, six subjects participated. Upon entering the lab, subjects were told they were not allowed to communicate with each other and they could use the computers only for the purpose of the experiment. Subjects received detailed instructions on their computer screens, which were read aloud. The instructions typically took 30 minutes, and the nine-period experiment added 45-60 minutes. Average earnings were approximately US\$ 50 (including a show-up fee).

In the experiment, three subjects played the role of low emitters and three that of high emitters. (One can think of low emitters as using natural gas and high emitters as using coal to generate electricity.) Low emitters required one permit for each unit produced and high emitters required two permits per unit produced. ${ }^{5}$ Each producer had a capacity limit of four units, with the marginal production costs for each of the four units being randomly drawn and known only to the producer. The cost draws were independent across producers and periods. ${ }^{6}$

3. Hahn (1984) shows that free allocations can cause inefficiencies, especially when a firm with market power receives more (or fewer) allowances than its cost effective allocation. In an experimental paper, Hahn (1983) finds that when the initial allocation deviates from the least cost allocation, a zero-revenue auction is less susceptible to market power than free distribution. Liski and Montero (2005) extend Hahn's work by looking at initial allocations over time and allowing banking of permits using a dominant firm/competitive fringe model.

4. The experiments were conducted at the University of Virginia using the VeconLab emission permit auction program, accessible at $\langle$ http://veconlab.econ.virginia.edu/ep/ep.php $\rangle$.

5. Industry data show that the emission rate (tons of $\mathrm{CO}_{2}$ per $\mathrm{MWh}$ of electricity) for gas-fired generation is about 0.43 times that for coal-fired generation.

6. The auction and grandfathering sessions were "paired" in that random cost draws used for an auction session were also used for a grandfathering session. We used new random cost draws across different auction sessions, for a total of seven independent pairs. 
Marginal production costs for low emitters were uniformly distributed on $[8,12]$ and those for high emitters were uniformly distributed on $[4,8] .{ }^{7}$ With a capacity of 4 units for each producer, permits would not be scarce if there were 36 or more (since the three low emitters would use at most 12 permits and the three high emitters would use at most 24 permits). Our choice was to reduce the number of permits to $50 \%$, that is, a cap of 18 permits, which shifts supply away from high emitters as we explain subsequently.

Each period of the experiment consisted of three stages: (1) the assignment stage (grandfathering or auction), (2) a spot market, and (3) the product market. In the assignment stage of the grandfathering treatment, each low emitter was endowed with two permits and each high emitter with four permits. No initial endowments were assigned in the auction treatment. Instead 18 permits were offered for sale in a uniform-price auction in which bids were ranked from low to high with the top 18 bids winning and the uniform price that winners paid being determined by the highest losing bid (i.e., the 19th highest bid).

After subjects had been informed about their initial endowments, or after they had learned the outcome of the auction, they were given the opportunity to trade permits in a spot market. The spot market was introduced to correct for initial mis-allocations. The spot market was modeled using a single-round, limit-order call market in which each producer was provided with a single opportunity to submit buy and/or sell orders. A buy order consisted of a quantity and a bid price equal to the maximum a producer was willing to pay for a permit. ${ }^{8}$ Likewise, a sell order specified a quantity and an ask price, which was the minimum a seller wanted to receive for a permit. ${ }^{9}$ The bid and ask prices were then ordered to form a demand and supply curve, respectively, and their intersection determined the market-clearing price. Buy orders with bid prices above the market-clearing price transacted, as did sell orders with ask prices below the market-clearing price. Once the market-clearing price and transactions had been determined, producers were informed about their new cash and permit holdings.

Finally, in the product market all six producers could specify sell prices for each of their four capacity units. If a producer preferred not to sell one or more units, then this could be done by selecting the "no bid" option from a drop-down menu of possible sell prices. The asks were ranked to form a supply curve, which was intersected with a commonly known demand function, $D(p)=$ $36-p$, to determine the equilibrium price. Only orders that specified prices less than the equilibrium price sold, and producers' cash and permit holdings were updated.

7. This assumption captures current industry conditions, namely, cleaner gas-fired plants face higher production costs than dirtier coal-fired plants.

8. The total dollar amount of a buy order could not exceed a subject's cash holdings.

9. The total number of permits listed in a sell order could not exceed a subject's permit holdings. 
The permit constraint was not binding in every period, that is, producers were allowed to be "non-compliant" by selling more units than they had permits for. If they sold fewer units than they had permits for, unused permits would carry over to the next period, that is, "banking" of permits was possible. However, in periods 3,6 , and 9 of the experiment, the program checked for compliance: A producer who had a permit deficit in any of these periods was charged a penalty of 16 for every missing permit.

\section{Theoretical Predictions}

The competitive equilibrium prices in the permit spot market and the product market, denoted $r$ and $p$, respectively, follow from a set of coupled demand-andsupply equations. Consider a low emitter with marginal cost $8 \leq c \leq 12$ for the first unit. Selling this unit results in a profit of $p-r-c$, since a low emitter needs one permit for each unit produced. Hence, a low emitter would sell the unit if and only if $p-r>c$. Because a low emitter's cost distribution is uniform on $[8,12]$, the expected supply of a low emitter is

$$
S_{L}(p, r)= \begin{cases}0 & \text { if } p-r<8, \\ p-r-8 & \text { if } 8 \leq p-r<12, \\ 4 & \text { if } 12 \leq p-r .\end{cases}
$$

Likewise, supply of a high emitter is

$$
S_{H}(p, r)= \begin{cases}0 & \text { if } p-2 r<4, \\ p-2 r-4 & \text { if } 4 \leq p-2 r<8, \\ 4 & \text { if } 8 \leq p-2 r .\end{cases}
$$

Competitive equilibrium prices now follow from the requirement that demand equals supply in the product market, $D(p)=3 S_{L}(p, r)+3 S_{H}(p, r)$, and that the total number of permits used is equal to the cap, $3 S_{L}(p, r)+6 S_{H}(p, r)=18$. It is readily verified that equilibrium price levels are $p=21$ and $r=8$. At these price levels, a low emitter produces four units (i.e., at full capacity) and requires four permits, whereas a high emitter produces one unit and needs two permits.

The introduction of a cap of 18 permits shifts supply away from high emitters; see the left panel of Figure 1 (the right panel is explained in Section 5). Demand is shown by the downward sloping thin black line, and supply is shown by the dotted lines for low emitters and by the solid lines for high emitters. When the cap is non-binding (i.e., 36 or more permits so $r=0$ ), the high emitters are on the bottom part of the supply curve since they have lower marginal production costs, as shown by the lower supply curve. However, with a binding cap of 18 

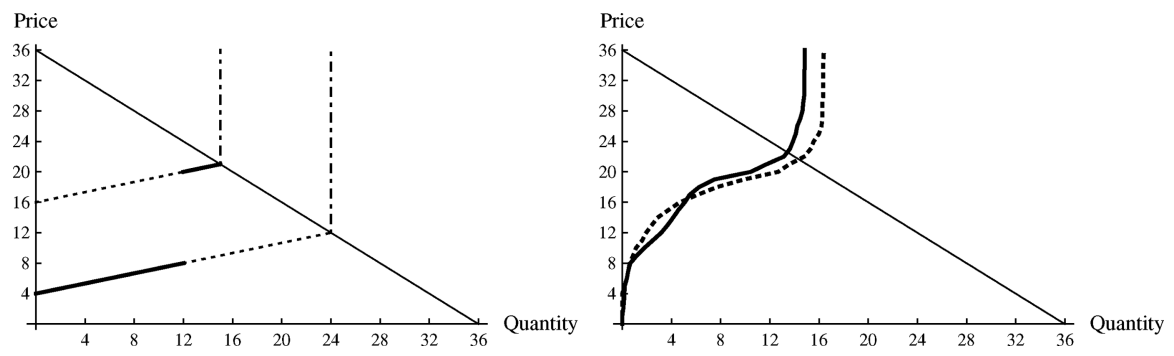

FIGURE 1. Left: demand and supply for a cap of 18 (upper supply curve) and 36 (lower supply curve). High (low) emitters' supply is shown by the solid (dotted) lines and the vertical dot-dashed lines reflect capacity or permit constraints. Right: observed supply with a cap of 18 under grandfathering (solid) and an auction (dotted line).

permits and a resulting equilibrium permit price of $r=8$, the low emitters have lower per-unit costs, as shown by the upper supply curve. The vertical line at a quantity of 24 reflects the production capacity constraint of 4 units for each of the six producers. The vertical line at a quantity of 15 reflects the permit constraint: The three low emitters have 12 permits and, hence, can produce 12 units, and the three high emitters have 6 permits and, hence, can produce only 3 units.

Low and high emitters' profits under the competitive equilibrium benchmark depend on how permits are initially assigned. Under grandfathering, a high emitter sells two permits at a price of $r_{S}=8$ in the spot market, and sells one unit at a price of 21 in the product market. The expected value of the lowest marginal cost of a high emitter is 4.8 , so a high emitter's profit is $16.2+16=32.2$. A low emitter sells four units in the product market for a profit of $4(21-10)=44$ and the low emitter acquires two permits in the spot market, so total net profits are $44-16=28$. In the auction, a low emitter is predicted to acquire four permits and a high emitter two permits at a unit price of $r_{A}=8$. Because auction-permit allocations are optimal, there is no predicted activity in the spot market. Total profits for low and high emitters are now $44-32=12$ and $16.2-16=0.2$, respectively. ${ }^{10}$

The competitive equilibrium predictions are shown in the top panel of Table 1. The Prices column shows the permit price ( $r_{A}$ in the auction, $r_{S}$ in the spot market, and NA is short for "not applicable") and the product market price ( $p$ ). The Permits column shows permit holdings of the low and high emitters after the assignment stage and after the spot market. Producers' overall profits are shown

10. In order to negate the effects of possible low earnings, we gave each high emitter an initial payment of US\$ 60 , whereas each low emitter only received US\$ 10 . These initial payments were the same in both treatments and were private information. After each session, subjects were paid in cash at a rate of $30 \%$ of experiment earnings. 
TABLE 1. Theoretical predictions and experimental outcomes.

\begin{tabular}{|c|c|c|c|c|c|c|}
\hline & $\begin{array}{c}\text { Prices } \\
\mathrm{r}_{\mathrm{A}}, \mathrm{r}_{\mathrm{S}}, \mathrm{p}\end{array}$ & $\begin{array}{l}\text { Permits } \\
\text { Assignment }\end{array}$ & $\begin{array}{l}\text { Low, High) } \\
\text { Spot Market }\end{array}$ & $\begin{array}{c}\text { Profits } \\
\text { Low, High }\end{array}$ & $\begin{array}{c}\text { Consumer } \\
\text { Surplus }\end{array}$ & $\begin{array}{c}\text { Government } \\
\text { Revenue }\end{array}$ \\
\hline $\begin{array}{l}\text { Competitive Equilibrium } \\
\text { Grandfathering } \\
\text { Auction }\end{array}$ & & & & $\begin{array}{c}28,32.2 \\
12,0.2\end{array}$ & $\begin{array}{l}112.5 \\
112.5\end{array}$ & $\begin{array}{c}0 \\
144\end{array}$ \\
\hline $\begin{array}{l}\text { No Trade } \\
\text { Grandfathering } \\
\text { Auction }\end{array}$ & $\begin{array}{c}\text { NA, NA, } 24 \\
8, \text { NA, } 21\end{array}$ & $\begin{array}{l}6,12 \\
12,6\end{array}$ & $\begin{array}{l}6,12 \\
12,6\end{array}$ & $\begin{array}{c}29.6,37.6 \\
12,0.2\end{array}$ & $\begin{array}{c}72 \\
112.5\end{array}$ & $\begin{array}{c}0 \\
144\end{array}$ \\
\hline $\begin{array}{l}\text { Observed (periods 5-9) } \\
\text { Grandfathering } \\
\text { Auction }\end{array}$ & $\begin{array}{c}\text { NA, } 11.0,22.6 \\
7.2,8.4,21.9\end{array}$ & $\begin{array}{c}6,12 \\
9.3,8.7\end{array}$ & $\begin{array}{l}8.2,9.8 \\
9.4,8.6\end{array}$ & $\begin{array}{c}28.4,35.7 \\
14.2,4.5\end{array}$ & $\begin{array}{c}90.0 \\
100.3\end{array}$ & $\begin{array}{c}0 \\
133.8\end{array}$ \\
\hline
\end{tabular}

in the Profits column, and the final two columns show consumer surplus and government revenue (from the auction or non-compliance penalties).

The competitive equilibrium benchmark assumes price taking behavior, which is not realistic if traders can exercise market power in the permit or product markets. ${ }^{11}$ As another benchmark, suppose no trade occurs in the spot market. High emitters will then produce two units and so will low emitters, yielding a product market price of 24 and profits of $48-4.8-5.6=37.6$ for high emitters and $48-8.8-9.6=29.6$ for low emitters; see the ("No Trade") panel of Table 1 .

\section{Results}

Aggregate statistics for the auction and grandfathering treatments are shown in the bottom ("Observed") panel of Table 1. The numbers represent data averages for the final five periods (periods 5-9) of the seven sessions in each treatment.

The auction permit price (7.2) is lower than predicted (8.0) and the resulting allocation of permits, 9.3 permits for low emitters and 8.7 permits for high emitters, reveals that too few permits are won by low emitters. This mis-allocation is not corrected in the spot market where trading volume is very low. ${ }^{12}$ The average spot market price (8.4) is higher than the auction price, which reflects a higher willingness-to-pay of producers who were unsuccessful in the auction and need additional permits to avoid the penalty. The post spot-market permit holdings

11. Or if they expect "information rents" resulting from private information about production costs, see Myerson and Satterthwaite (1983).

12. On average only 0.46 permits are traded: 0.26 permits are bought by emitters of the same type (i.e., a low emitter buying from another low emitter, or a high emitter buying from another high emitter), 0.06 permits are bought by high emitters from low emitters, and 0.14 permits are bought by low emitters from high emitters. So the net permit transfer from high to low emitters is only 0.08 . As a result, permit allocations are almost unaffected by the spot market: The low emitters hold 9.4 permits on average, and the high emitters 8.6. 

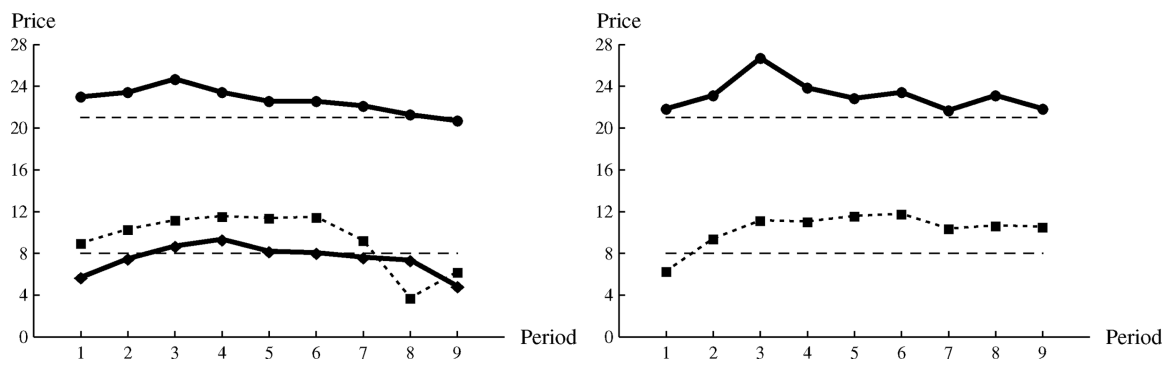

FIGURE 2. Permit and product prices using auctions (left) and grandfathering (right).

The solid line with diamond markers show auction permit prices, the dotted lines with square markers show spot-market permit prices, and the solid lines with circle markers show product prices. The thin dashed lines show theoretical predictions.

explain why observed output in the product market (14.1) is less than the competitive equilibrium output (15.0). The associated higher product price of 21.9 lowers consumer surplus (100.3) and benefits producers. The observed profit for a low emitter is 14.2 while high emitters make a small profit of 4.5 , partly because they incur an average compliance penalty of 3.7. Finally, the average auction revenue is 130.1 , which translates into a government revenue of $130.1+3.7=133.8$.

With grandfathering, on average 3.7 permits are being traded in the spot market, resulting in a net transfer of 2.2 permits from high to low emitters. ${ }^{13}$ So the spot market corrects the initial mis-allocation to some extent but not nearly as much as a competitive equilibrium analysis predicts. The spot-market price for permits is 11.0, which is higher than in the auction. Output in the product market is 13.4 and the product price is 22.6, with low consumer welfare (90.0) and high profits as a result (28.4 for low emitters and 35.7 for high emitters). There are no non-compliance penalties so government revenue is 0 .

Figure 2 shows prices for different stages in the auction (left) and grandfathering (right) treatments. The top solid lines (circle markers) correspond to prices in the final product market, and the dashed line at a price level of 21 is the theoretical prediction. Note that with grandfathering, product prices are somewhat higher. The reason is that more permits are owned by high emitters and, as a result, total output is less. The bottom solid line (diamond markers) in the left panel shows the permit prices in the auction, and the dashed line at a price level of 8 is the theoretical prediction. Finally, the dotted lines (square markers) show the permit prices in the spot market. Note that with the auction, spot prices are too high but drop towards the equilibrium level of 8 in the final periods. In contrast, with

13. On average, 1.3 permits are traded are among high emitters only or among low emitters only, and 0.1 permits are bought by high emitters from low emitters. 

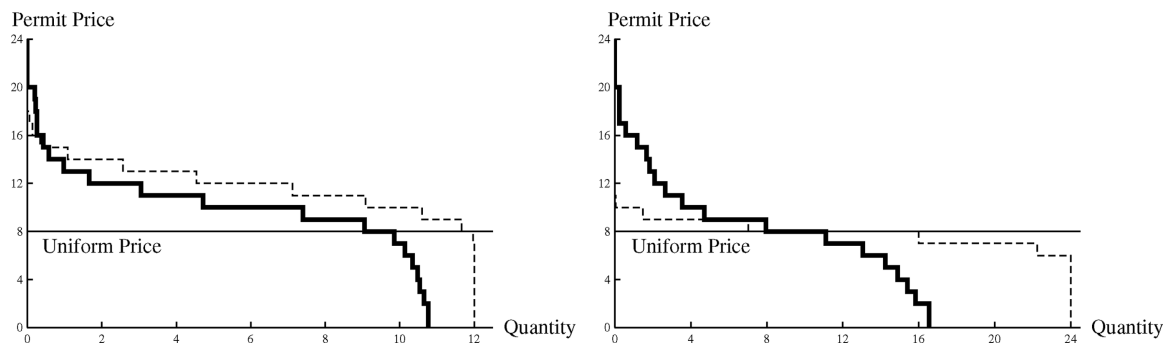

Figure 3. Low emitters' demand (left) and high emitters' demand (right) for permits in the auction.

The dashed lines show theoretical predictions based on truthful bidding.

grandfathering, high emitters exercise their market power in the permit market and drive up the permit price to 11 in the second half of the experiment. ${ }^{14}$

\section{Market Power}

In this section we consider the following three questions, raised by the experimental results reported herein. In the auction, why are too few permits won by low emitters? Under grandfathering, why are too few permits traded from high to low emitters? What is the degree of pass-through under grandfathering where permits are obtained for free?

Figure 3 shows demand for permits in the auction by low emitters (left) and high emitters (right). The dashed line gives the theoretical prediction when demand is "truthful," that is, when bids are equal to values. The left panel shows that low emitters behaved like "monopsonists"- because they are the larger buyers in the auction, low emitters strategically withheld demand to push down the price. In contrast, some high emitters submitted bids that exceeded their values to ensure they received some permits. Consequently, high emitters won more than the predicted number of permits, as can be seen from intersecting the horizontal line at a price of 8 with the relevant demand curves, yielding 9.3 permits for low emitters and 8.7 permits for high emitters. To summarize, although the auction awards the majority of the permits to the low emitters, there is some degree of misallocation because of strategic demand reduction by the low emitters (monopsony power) and some overbidding by high emitters.

Figure 4 shows demand and supply in the permit spot market under grandfathering. The solid downward sloping line represents demand (of mostly low

14. Figure 2 provides some evidence for adjustments in subjects' behavior over time (learning), for example, spot prices in the grandfathering treatment show a significant time trend up to period 5 after which they level off, which is the reason that the aggregate statistics reported in Table 1 are based only on the final five periods of the experiment. 


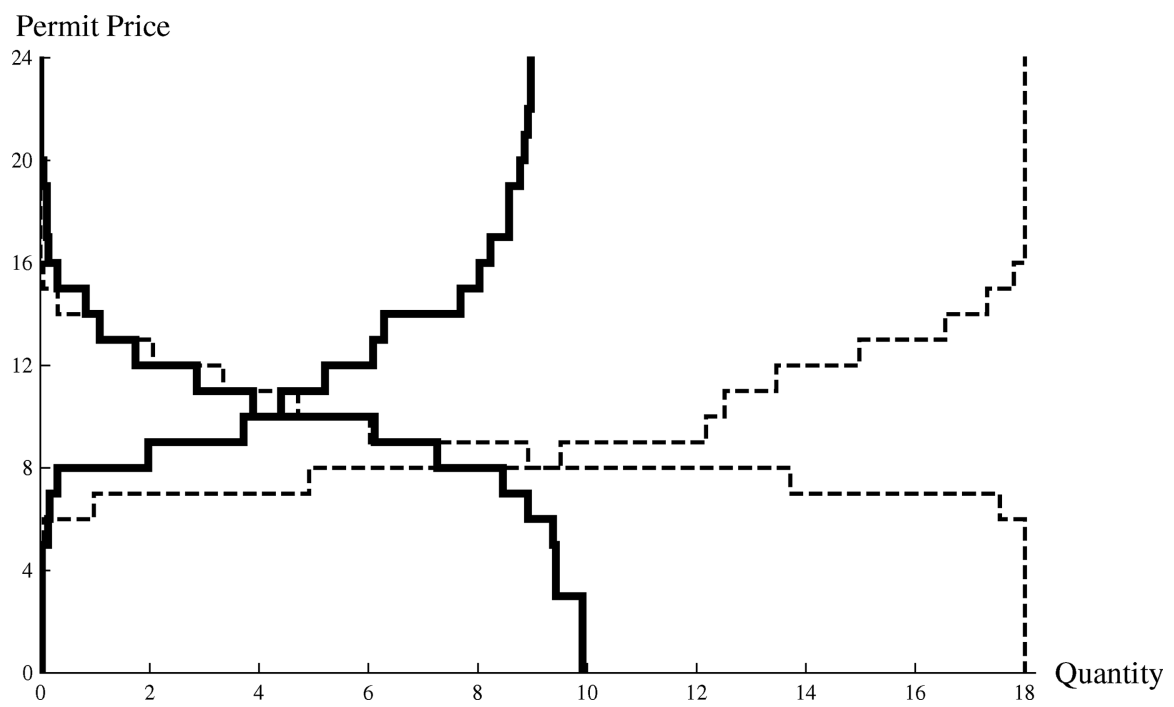

FIGURE 4. Observed (solid) permit demand and supply in the spot market under grandfathering, aggregated over low and high emitters, and predicted (dashed) demand and supply, constructed by equating bids/asks to values.

emitters) and the upward solid line shows supply (of mostly high emitters). The thin dashed lines represent predicted demand and supply when bids and asks are truthful. Notice that observed demand is close to truthful in the relevant range, but that observed supply differs starkly from predicted supply. Some high emitters may be withholding supply strategically to raise price, but others may be reacting behaviorally to maintain their endowments in a process that is reinforced by the high realized profits that result. Either way, the market power is due to larger allocations for high emitters under grandfathering, and the spot market does not fully correct initial mis-allocations under grandfathering. ${ }^{15}$

Finally, in the discussion about auctions versus grandfathering, one of the main issues is that of pass through, that is, whether auctions will cause producers to charge higher prices to recover permit costs (which are zero under grandfathering). ${ }^{16}$ The right panel of Figure 1 shows the distribution of ask prices in the auction (dotted line) and grandfathering (solid line) treatments. These empirical supply curves were constructed by considering the ask prices from both low and high emitters and taking an average over the final five periods of each of the

15. A standard markup-over-cost computation yields $(p-c) / p \times 100 \%=16 \%$, on average, where $p$ is the observed ask price and $c$ the true value of the permit.

16. A referee suggested an alternative treatment to test for the irrelevance of sunk costs by having a control group with the same allocation of permits as in the auction. This is an interesting extension although the (ir)relevance of sunk costs is not the primary issue that motivated our study. 
seven sessions within a treatment. Note that for some of the inframarginal units (corresponding to very low marginal costs of production), the ask prices under grandfathering are indeed lower. However, for marginal units, which determine consumer prices, the opposite is true and ask prices are higher with grandfathering. In other words, the opportunity costs of "free" permits were fully "passed through" to the product market, resulting in large increases in producer profits in these sessions: earnings of low emitters doubled with free allocations, and earnings of high emitters increased even more sharply. ${ }^{17}$ These results are consistent with observed practices in the European carbon-trading market where Germanybased RWE collected billions of dollars in windfall profits from having obtained permits for free, and yet raised consumer electricity prices to reflect the permits' opportunity costs (see the Introduction).

\section{Conclusions}

Recall from the Introduction the two main issues addressed by this study: (1) Will auction-based allocations result in higher product prices? and (2) Will grandfathered allocations lead to inefficiencies in the way that permits are allocated to high-emitting and low-emitting producers? The laboratory experiments reveal that even free allocations of emissions permits result in dramatic increases in downstream product prices. ${ }^{18}$ It would be a mistake to adopt grandfathered procedures in the hope that the effects of cap-and-trade regulations will have no price consequences. In our laboratory markets, the price effects of free allocations were exaggerated by the tendency for high emitters, with large "history-based" permit allocations, to exercise some market power in the secondary markets for permits that preceded the clearing of the product market. The permit prices in these spot markets were well above competitive predictions. As a result, high emitters, who began with high allocations, entered the production phase with more permits than was optimal, which tended to reduce output and raise product prices. In contrast, permit prices tended to converge to competitive levels when permits were assigned by auction. The initial assignments resulting from the auction were more favorable to low emitters, which resulted in slightly lower product prices

17. The degree of pass through we observe is more pronounced than observed by Wråke et al. (2009) in a simple "individual decision" experiment where markets for permits and the downstream product were simulated exogenously. In the Wråke et al. experiment, some subjects had difficulty recognizing the opportunity cost of permits that were received for free, although behavior tended to get closer to theoretical predictions with experience. Benz and Ehrhart (2007) also study the effects of initial permit allocations in an experiment, but the issue of pass through was not addressed.

18. These results are in line with a study that compares cell phone prices in Europe where some countries assigned 3G spectrum licenses by auction whereas others allocated the licenses for free via "beauty contests." The findings are that consumer prices are higher in, for instance, Spain where licenses were awarded for free than in, for instance, Germany and the UK where licenses were sold by auction at very high prices; see 〈http://dx.doi.org/10.1787/622303805401〉. 
and higher consumer welfare. The main effect of the auction is to transfer the windfall profits of (high) emitters into government revenue.

\section{References}

Benz, Eva, and Karl-Martin Ehrhart (2007). "The Initial Allocation of CO2 Emissions Allowances: A Theoretical and Experimental Study." Discussion paper, University of Bonn. Burtraw, Dallas, Karen Palmer, Ranjit Bahrvirker, and Anthony Paul (2002). "The Effects on Asset Values of the Allocation of Carbon Dioxide Emission Allowances." Electricity Journal, 15(5), 51-62.

Hahn, Robert W. (1983). "Designing Markets in Transferable Property Rights: A Practitioner's Guide." In Buying a Better Environment. Cost-Effective Regulation Through Permit Trading, edited by Erhard F. Joeres and Martin H. David. University of Wisconsin Press.

Hahn, Robert W. (1984). "Market Power and Transferable Property Rights.” Quarterly Journal of Economics, 99(4), 753-765.

Liski, Matti, and Juan-Pablo Montero (2005). "A Note on Market Power in an Emission Permits Market with Banking." Environmental and Resource Economics, 31(2), 159-173.

Myerson, Roger B., and Mark A. Satterthwaite (1983). "Efficient Mechanisms for Bilateral Trading." Journal of Economic Theory, 29, 265-281.

Wråke, Markus, Erica Myers, Svante Mandell, Charles A. Holt, and Dallas Burtraw (2009). "Pricing Strategies under Emissions Trading: An Experimental Analysis." Discussion paper, Swedish Environmental Research Institute. 